\title{
Curtailing Unhealthy Consumption of Alcohol for Sustainable Development in India and South Africa
}

\author{
Praise Marara1, Seema Rath², Samridhi Sharma1, Sean James Bosman³, Sunitha Srinivas ${ }^{1 *}$ \\ ${ }^{1}$ Faculty of Pharmacy, Rhodes University, Grahamstown, SOUTH AFRICA. \\ ${ }^{2}$ Hugh Kelly Fellow, Faculty of Pharmacy, Rhodes University, SOUTH AFRICA/Department of Economics, Government College, \\ Khandola-Goa, INDIA. \\ ${ }^{3}$ Department of English, Rhodes University, Grahamstown, SOUTH AFRICA.
}

\begin{abstract}
Alcohol consumption has been a major contributor to the global burden of diseases, accounting for 3.3 million deaths, which is equivalent to $5.9 \%$ of all global deaths. Alcohol misuse is the fifth leading risk factor for premature death and disability, and is the top factor among people between 15 and 49 years. There are causal relationships between the harmful use of alcohol and incidences of both non-communicable diseases and infectious diseases such as STIs, including HIV/AIDS. In addition to health consequences, the harmful use of alcohol also causes significant social and economic losses to individuals and society. This article focuses on alcohol consumption in India and South Africa, and highlights the policies that have been adopted in both countries and discusses interventions that could be used to combat it. Though policies and interventions have been put into place, gaps exist because alcohol use is high, especially in South Africa, and continues to rise in both countries. Strategies to reduce the harmful use of alcohol include the adoption of national policies and educational interventions such as health promotion. To reduce the harmful use of alcohol, the World Health Organization Global Strategy provides an initial framework that countries can adopt. South Africa's national policy follows this framework, while in India, alcohol remains a state/province controlled subject. A well formulated national policy on alcohol use, when implemented effectively, could have a positive effect on sustainable development.
\end{abstract}

Key words: Harmful Use of Alcohol, Non-Communicable Diseases, Infectious Diseases, India, South Africa.

\section{INTRODUCTION}

The harmful use of alcohol is a global problem resulting in individual, social and economic implications. ${ }^{1}$ Tobacco and alcohol are responsible for a major part $(8.1 \%)$ of the disease burden, with alcohol being the top risk factor for bad health in developing countries. ${ }^{2}$ Globally, alcohol use is the third leading risk factor for poor health and is the number one risk factor causing disease and death in people aged $15-49$ years, which is economically the most productive group. ${ }^{1}$ Alcohol is also one of the main factors contributing to premature deaths and disability and has a major impact on public health. Changing social norms, urbanization, increased availability, high intensity mass marketing and relaxation of overseas trade rules, along with poor levels of awareness of the consequences of harmful use of alcohol, have contributed to increased alcohol use, resulting in epidemiological transitions. ${ }^{3,4}$ There is considerable evidence suggesting that an increase in alcohol prices reduces consumption and the level of alcohol-related problems. $^{5}$

The United Nations Millennium Development Goals (MDGs) are eight goals that all 189 UN member States agreed to try to achieve by the year $2015 .{ }^{6}$ Not all of the MDGs were fully achieved by the target date, with a number of global targets missed. ${ }^{7}$ Alcohol affects at least five of these eight MDGs. The first MDG, aimed at eradicating extreme poverty and hunger, is affected by alcohol, as disastrous alcohol expenditure may result in people in poor communities getting into lifelong debts. Achieving universal primary education, i.e.
DOI: 10.5530/ijopp.9.2.4

Address for correspondence: Sunitha Chandrasekhar Srinivas, Faculty of Pharmacy, Rhodes University PO Box 94,

Grahamstown, SOUTH AFRICA.

Phone no: + 27466038496 E-mail: s.srinivas@ru.ac.za

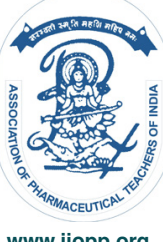

www.ijopp.org 
MDG 2, was indirectly affected by alcohol, since its dependence and abuse has an impact on jobs being lost, exacerbating shortages in resources to invest on children's primary education. ${ }^{8}$ Promoting gender equality and empowering women (MDG 3) was affected by alcohol, since alcohol-related problems are associated with increased risk of male intimate partner violence against women. ${ }^{9}$ Combatting HIV/AIDS, i.e. MDG 6, was also affected by alcohol misuse, as excessive alcohol consumption weakens the immune system, making the body more prone to HIV infection and sexually transmitted infections. ${ }^{8}$ Sustainable Development Goals (SDGs) set the new agenda that are relevant to all countries worldwide to be achieved by $2030 .^{7}$ The SDGs aim to reduce premature mortality from NCDs by one third through prevention and treatment; to promote mental health and well-being; and to strengthen the prevention and treatment of substance abuse, including narcotic drug abuse and the harmful use of alcohol. ${ }^{10}$

\section{TREND IN ALCOHOL USE}

Per capita sales of alcohol and tobacco are decreasing in high-income countries (HICs), but increasing in lowand middle-income countries (LMICs). While alcohol consumption is reportedly decreasing in the developed world, it is increasing in developing countries, including India. ${ }^{1}$ The rate of increase in consumption of "unhealthy commodities" (such as soft drinks and processed foods that are high in salt, fat, and sugar, as well as tobacco and alcohol) is highest in LMICs, with little or no further growth expected in HICs. ${ }^{11}$ Also, patterns of drinking to intoxication are more prevalent in developing countries, indicating higher levels of risk due to drinking. ${ }^{3}$

\section{Alcohol consumption in South Africa and India}

The World Health Organization states that South Africa has one of the highest levels of alcohol consumption in the world, with 16.6 liters of pure alcohol consumed per drinker per year. This pattern of drinking is similar to those in Kazakhstan, Mexico, Russia and the Ukraine, which are known for their high alcohol consumption. ${ }^{12,13}$ The WHO Global Alcohol Report 2014 shows that the total alcohol per capita consumption for the population aged 15 and above, for drinkers in South Africa, was 32.8 litres of pure alcohol in males and 19.6 litres of pure alcohol in females. Over the years, alcohol consumption has increased and still remains more dominant in males than in females. ${ }^{14}$ The WHO gives South Africa a score of four out of five (i.e. drinking 5 or more beers or glasses of wine at one sitting for men, and more than 3 drinks for women). On a least risky to most risky patterns-of-drinking scale, the higher the score, the greater the alcohol-attributable burden of disease for the country. ${ }^{15}$ There is greater harm per liter of alcohol consumed in South Africa than in other regions, where drinking prevalence may be more widespread but where harmful use is rare. Consequently, South Africa experiences alcohol-related costs and externalities above global averages. ${ }^{12}$ Alcohol consumption is significantly higher in South Africa than in India (Table 1). In South Africa, nearly half of the alcohol consumption is in the form of beer, while in India, spirits make up 93\% of the total alcohol consumed.

India was among the countries with low alcohol consumption levels, but recent consumption levels of alcohol have increased due to liberalized social values, a lack of evidence based research in this area, expansion in commercial production, and aggressive marketing campaigns by the alcohol industry. ${ }^{1,16}$ Due to its large population, India has been identified as potentially the third largest market for alcoholic beverages, just behind China and Russia, attracting the attention of multinational liquor companies. ${ }^{3}$ India is the dominant producer of alcohol (65\%) in the South East Asia Region and contributes to about $7 \%$ of total alcohol beverage imports into the region. India is now one of the key markets for the global spirits industry and alcohol is the most commonly used intoxicating substance in the country. ${ }^{1,17}$ The total alcohol per capita consumption for drinkers (aged 15+) in India was 32.1 litres of pure alcohol in males and 10.6 litres of pure alcohol in females, showing that men consume almost three times as much as females, with drinking patterns showing to be average, as the score was three out of five. ${ }^{17}$ Over the years, alcohol consumption has increased and still remains more dominant in males than females. ${ }^{15}$ Although India's consumption of alcohol is still low when compared to the rest of the world, $32 \%$ of Indians consume alcohol, out of which $4-13 \%$ are daily consumers. ${ }^{16}$ Sale of alcohol has been growing steadily at $6 \%$ and is estimated to grow at the rate of $8 \%$ per year. The percentage of the drinking population aged below 21 years has increased from $2 \%$ to more than $14 \%$ in the past 15 years. People drink at an earlier age than before, and the "mean age of initiation" has dropped from 19 to 13 years over the past two decades. ${ }^{1,3}$ Table 2 shows that the extent of harmful consumption of alcohol in South Africa is very high compared to India.

\section{IMPACT OF HARMFUL USE OF ALCOHOL}

Alcohol abuse is a major concern and causes socioeconomic problems in many developing countries. It places a burden on the social, economic and health wellbeing of irresponsible drinkers as well as on their social support networks. ${ }^{18}$ The negative consequences 


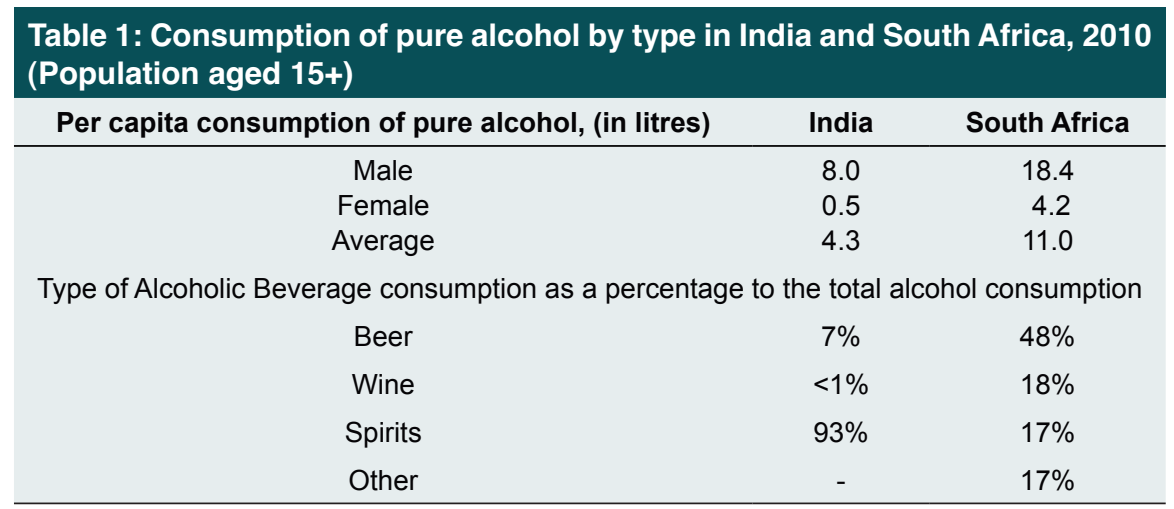

Source: WHO, NCDs Country Profile 2014; WHO, Global status report on alcohol and health $2014 .{ }^{43}$

\begin{tabular}{|ccc|}
\hline Table 2: Extent of Harmful Consumption of Alcohol in India and South Africa, 2010 \\
\hline Harmful Consumption of Alcohol & India & South Africa \\
\hline Heavy episodic drinking, past 30 days (\%) & 3.2 & 17.5 \\
Males & 0.0 & 2.9 \\
Females & 1.6 & 9.8 \\
Both sexes & & \\
Alcohol use disorders, 12 month prevalence (\%) & 4.4 & 9.6 \\
$\quad$ Males & 0.5 & 1.5 \\
Females & 2.5 & 5.4 \\
\hline
\end{tabular}

Source: WHO, Global Status Report on NCDs, 2014.44

of the harmful use of alcohol also have substantial cost implications for the government. ${ }^{12}$

\section{Social and Economic Consequences}

Harmful use of alcohol is a pattern of alcohol use that causes damage to health, which can be physical or mental, for example depressive episodes secondary to heavy alcohol intake. ${ }^{19}$ The harmful use of alcohol includes several aspects of drinking, such as the volume of alcohol drunk over time; the pattern of drinking (frequency of drinking); the drinking context, if it increases the public health risks; and the quality of the alcoholic beverages. ${ }^{1}$ Emotional and psychological impacts on families, the high levels of crime and other social ills have left many communities under siege by the scale of alcohol and drug consumption. Harmful drinking leads to negative social consequences for the user, the people around the user, society at large and the government. ${ }^{18,20}$ Alcohol use is often a contributing factor in crimes, misdemeanors and accidents. For example, alcohol is involved in more than $50 \%$ of interpersonal violence cases. Similarly, in transport fatalities, alcohol is associated with $53 \%$ of all cases. ${ }^{12}$ The extent of harmful consumption of alcohol in South Africa is very high compared to India (Table 2).

Alcohol consumption can affect the workplace through absenteeism. People with alcohol dependence and drinking problems are on sick leave more frequently than other employees, leading to a significant cost to employees, employers, and to social security systems. ${ }^{21}$ In India, $20 \%$ of absenteeism and $40 \%$ of accidents at the work place are alcohol related. ${ }^{3}$ Productivity may decrease with heavy drinking at the workplace. Drinkers have lower performance, problems in personal relationships with co-workers, and lack self-direction, although drinkers themselves may not feel as though their work performance is being affected. Heavy drinking or alcohol abuse may lead to unemployment, which in turn may lead to increased drinking. ${ }^{21}$

Drinking can affect how a person behaves as a parent and as a partner. ${ }^{21}$ Eighty five percent of men who were violent towards their wives were frequent or daily users of alcohol. More than half of abusive incidents occurred under the influence of alcohol. ${ }^{3}$ The impact of drinking on family life can include substantial mental health problems for other family members, such as anxiety, fear and depression, and child mistreatment..$^{21,22}$ Use of alcohol increases indebtedness and reduces the ability to pay for food and education, and can leave the family in destitution as funds for household expenditure are diverted to purchase alcohol. ${ }^{1}$ Alcohol abuse leads to separations and divorces and causes emotional hardship for the family. While the emotional trauma cannot be 
translated into monetary terms, the impact it has on the quality of lives is significant. ${ }^{3}$

\section{Health Consequences}

Consumption of alcohol has been identified as one of the main determinants of NCDs. There are strong links between alcohol and several of the main NCDs. NCDs are a major threat to development in developing countries. ${ }^{23}$ Alcohol has been linked to cancer, cardiovascular diseases (CVDs), liver diseases and mental disorders. According to the Global Burden of Disease report (GBD) 2010, the burden of disease attributable to alcohol consumption in 2010 was substantial. It accounted for 4.9 million deaths and $5.5 \%$ of global DALYs in $2010 .{ }^{21}$ Of the NCDs associated with alcohol use, the largest number of DALYs are due to alcohol dependence (about 120,000 DALYs per year), followed by cirrhosis of the liver (74,000 DALYs), epilepsy (52,000 DALYs) and hypertension (32,000 DALYs). ${ }^{12}$

Chronic alcohol consumption, particularly heavy drinking occasions, can contribute to high blood pressure, abnormal heart rhythms, heart failure, and strokes. Alcohol is associated with various kinds of liver diseases, with fatty liver, alcoholic hepatitis and cirrhosis being the most common. Drinking $30 \mathrm{~g}$ of absolute alcohol per day is associated with an increase in the chance of dying from liver cirrhosis. Morbidity and mortality increase with the volume consumed per day. ${ }^{21}$

Alcohol intake during pregnancy can cause spontaneous abortion, slower fetal growth in the womb, premature birth, low birth weight and Fetal Alcohol Spectrum Disorder. ${ }^{21}$ Previous studies show the typical woman at risk to an alcohol exposed pregnancy as being poorly educated and living in poverty. ${ }^{24}$ Targeting drinking during pregnancy is therefore important to reduce adverse health effects on the developing fetus. ${ }^{25}$

Alcohol use is a major underlying factor in homicides, violence, road traffic deaths, suicides, and other, unintentional injuries across South Africa. ${ }^{26}$ Hazardous drinking was also significantly associated with severe health problems, such as head injuries, and hospitalizations. In India, $34 \%$ of those who attempted suicide were abusing alcohol. ${ }^{3}$

\section{POLICIES AND INTERVENTIONS TO REDUCE HARMFUL USE OF ALCOHOL IN SOUTH AFRICA AND INDIA}

To address NCDs, countries can implement the Global Strategy to Reduce the Harmful Use of Alcohol, which provides an initial international framework for action and was approved by the World Health Assembly (WHA) in Geneva in May 2010, subsequently being adopted by the 193 member States. ${ }^{4,26}$ Evidence-based strategies that have the potential to reduce the occurrence of heavy drinking episodes and the prevalence of alcohol use disorders affecting NCDs are recommended to be implemented. Such strategies are likely to include regulating the availability, pricing and marketing of alcohol. Improvements to the capacity of health services could support such initiatives by screening for risk and conducting brief interventions for hazardous and harmful drinking at primary healthcare facilities and other settings. ${ }^{25}$

While alcohol is an individual-level risk factor, its consequences can be prevented via broader public health interventions, such as those impacting on its availability, affordability and marketing. ${ }^{23}$ Strategies for health promotion and for prevention require both population and individual level interventions. ${ }^{2}$ Community support networks are responsible for implementing policies, programmes and plans to address alcohol abuse. Collaboration between the private sector and the alcohol industry is important to develop and implement such policies. ${ }^{22}$ Sustainable policy approaches rely on the involvement of the private sector, including employers and shareholders. Policies that have support from a wide range of partners are more likely to succeed and be acceptable to a larger proportion of the target population, therefore progressively becoming clear that multisectorial action is needed to implement and cover the gaps in existing policies. ${ }^{28,29}$

Both India and South Africa have introduced various policies and strategies (Table 3) to reduce the harm caused by and to curtail alcohol abuse. The Government of South Africa introduced legislation to deal with its supply and demand, such as NDMP (2013-2017), the Prevention and Treatment of Drug Dependency Act (20 of 1992), as amended, as well as the Prevention of and Treatment for Substance Abuse Act (70 of 2008). ${ }^{18}$ The Department of Health, Government of South Africa (DOH,SA) has developed a framework for legislation on the control of alcohol. The Department is in charge of reducing alcohol demand and the harm caused by alcohol, by making the alcohol related legislation and policy guidelines available to the public. It collaborates with the Departments of Education and Social Development on national awareness campaigns ${ }^{22}$ to this end. Therefore continuous evaluation of policies and intervention strategies is critical to ensure that a dynamic situation is given attention, and that the challenges are addressed. ${ }^{18}$

The NDMP aims to reduce socioeconomic and other costs associated with alcohol abuse, and to promote the development of a responsible and sustainable liquor industry, and makes provision for public participation 
Table 3: The Policies and Strategies implemented to Reduce Alcohol Consumption in India and South Africa

\begin{tabular}{|c|c|c|}
\hline Policies, Strategies and interventions & India & South Africa \\
\hline Written national policy/ national action plan & No & Yes \\
\hline Excise tax on alcohol & Yes & Yes \\
\hline Minimum legal drinking age & $\begin{array}{c}\text { Subnational } \\
6 \text { States-18yrs } \\
18 \text { States-21yrs } \\
5 \text { States - 25yrs }\end{array}$ & 18 years \\
\hline Licensing of days and hours of sale & $\begin{array}{l}\text { Yes in } 28 \text { states } \\
\text { No in } 2 \text { states }\end{array}$ & Yes \\
\hline Restrictions on outlet density & $\begin{array}{l}\text { Yes in } 22 \text { States } \\
\text { No in } 8 \text { states }\end{array}$ & No \\
\hline Licensing of places for sale and consumption & Yes & Yes \\
\hline Minimum sale price & $\begin{array}{l}\text { Yes in } 22 \text { States } \\
\text { No in } 8 \text { States }\end{array}$ & No \\
\hline $\begin{array}{c}\text { National BAC when driving a vehicle (general/young/ } \\
\text { professional) }\end{array}$ & $0.03 / 0.03 / 0.03$ & $0.05 / 0.05 / 0.02$ \\
\hline State regulations for restrictions on alcohol advertising & $\begin{array}{c}\text { Yes in } 13 \text { States } \\
\text { No in } 15 \text { States } \\
\text { Ban on direct surrogate ads in } 2 \text { States }\end{array}$ & No \\
\hline Prohibition on point of sale advertising & $\begin{array}{l}\text { Yes in } 5 \text { States } \\
\text { No in } 25 \text { States }\end{array}$ & No \\
\hline Legally required health warning labels on alcohol & $\begin{array}{l}\text { Yes in } 21 \text { States } \\
\text { No in } 9 \text { States }\end{array}$ & Yes \\
\hline Ban on sales and drinking in public places & Yes & Yes \\
\hline Government monopoly on retail sales & Yes & No \\
\hline
\end{tabular}

Source: WHO alcohol report 2014; Alcohol marketing and Regulatory Policy Environment in India $2013 .{ }^{30,45}$

in the liquor licensing process. ${ }^{22}$ The NDMP sets the roles of various government departments at national and provincial level, and identifies the need for a significant contribution to be made by other stakeholders in the country. ${ }^{26}$ For the purpose of the NDMP, the Department of Trade and Industry is responsible for the regulation of the liquor industry, as it enforces the Liquor Act (No. 59 of 2003) through the National Liquor Authority (NLA). The Liquor Act provides the norms, standards, and criteria for cooperative government in the regulation of alcohol in South Africa. The Act also provides for the establishment of the National Liquor Policy Council (NLPC), which consists of the Minister of Trade and Industry, as chairperson, and all MECs responsible for the administration of liquor matters in each province. ${ }^{22}$

To further strengthen the alcohol policy and practice in South Africa, various gaps need to be addressed, including intervention-focused demonstration projects and regular audits of treatment services and prevention programmes. ${ }^{2}$ Research recommends that interventions can be developed through legislation and regulation, and could include pricing regulation and taxation, restrictions on the availability of alcohol, direct drunkdriving interventions, community mobilization, education and public awareness interventions in the drinking environment. ${ }^{1,12}$ The DOH, SA is following the WHO's Global Strategy to Reduce the Harmful Use of Alcohol, while the liquor industry's strategy is to focus on educating consumers about responsible alcohol use. ${ }^{27}$ Shifting from national and community-based strategy devising approaches to community-specific solutions and community interaction with industry is vital for better implementation and enforcement. ${ }^{26}$ The alcohol industry is committed to reducing alcohol-related harm and for promoting policies, but they may lack the necessary expertise or the integrity to develop and implement such policies effectively. ${ }^{29}$ These interventions may provide a more cost effective means of limiting the harmful impact of alcohol misuse on the economy. ${ }^{25}$

The Constitution of India includes prohibition of alcohol in Article 47 of the Directive Principles of State Policy, but an effective, comprehensive, national alcohol control policy is essential. ${ }^{17}$ Alcohol is a state subject, and most state policies aim at making profits from the sale of alcohol products. ${ }^{30}$ Different policies govern different aspects of alcohol in each Indian state. There is need for a comprehensive national policy that, at a minimum, would set standards for how states regulate alcohol production, distribution and consumption. ${ }^{1}$

The 'public health approach' looks at the bigger picture concerning alcohol (e.g. the legal age to drink alcohol 
is 18 and above), those who drink alcohol (e.g. random breath testing), and the environment (including the accessibility and availability through policy and legislative interventions, e.g. times at which alcohol is sold), to reduce alcohol misuse by making the environment less 'pro-alcohol' and thereby reducing the per capita consumption. ${ }^{1,25}$

\section{Advertising}

A ban on all direct or indirect alcohol marketing may help to reduce the number of people initiating alcohol use. ${ }^{16}$ South Africa's Ministry of Health follows the 'public health approach' and has hence proposed tighter restrictions on alcohol advertising, recently tabling legislation that aims to ban alcohol advertising. ${ }^{12}$ Most of the Indian states that impose a ban on advertisements of alcohol brands do not clearly ban indirect advertising such as promotion and sponsorship. Alcohol companies advertise their products indirectly in such states. Therefore it is critical that all states impose a comprehensive ban on all kinds of direct and indirect advertisements of alcohol brands. ${ }^{30}$ Only four states currently prohibit advertising alcohol brands at points of sale. ${ }^{1}$

\section{Pricing regulation and taxation}

In India, alcohol companies can change/increase the price of their products only once a year, when the state governments determine the alcohol prices. Thus state governments have a lot of control over alcoholic products, and this can be effectively used to regulate alcohol. ${ }^{30}$ Excise duties on alcohol are levied as a specific tax. When excise taxes increase, they are passed onto consumers as higher prices, which will generally lead to a reduction in alcohol consumption. Raising prices and taxes on alcohol is one of the most effective interventions to reduce alcohol consumption. ${ }^{16}$ Increasing excise taxes on alcohol should be to correct the extraneous costs of alcohol consumption, and to fund programmes that aim to reduce the burden of alcohol misuse. ${ }^{12}$ Increases in alcohol taxes have been associated with reductions in motor vehicle fatalities, crime, cirrhosis, industrial injuries and premature school leaving. ${ }^{25}$

Excise policies of the thirty Indian states show that there are many policy gaps, and that most excise policies are not comprehensive. The national Indian population is exposed to different sets of requirements of excise policies in each state. ${ }^{30}$ In India, tax generated from alcohol production and sale is the major source of revenue in most states, and has been cited as a reason for permitting alcohol sale. ${ }^{3}$ Introduction of a government monopoly for the retail and/or wholesale alcohol market may help to limit the harms attributable to alcohol use. ${ }^{16}$ In the southern states and some others, like Rajasthan, Orissa and Chhattisgarh, state governments have a monopoly over alcohol distribution. These states, especially Tamil Nadu, are considered role models for the collection of excise from alcohol. ${ }^{30}$ Their objective is to maintain control over the quality of alcohol, its price and taxation, and to prevent illegal alcohol sale. Apart from the taxes on the final alcohol product, duties on interstate movement of alcohol are also levied, thereby increasing the price. ${ }^{1}$ The rise in price is expected to reduce the harmful use of alcohol. ${ }^{31}$

\section{Restrictions on the availability of alcohol}

Alcohol is readily available in most communities in both licensed and unlicensed outlets in South Africa. ${ }^{24}$ One of the outcomes stated by the NDMP is to reduce the availability of dependence-forming substances/drugs, including alcoholic beverages. ${ }^{26}$ Considering the burden associated with acute alcohol intoxication, prevention of drinking to marked intoxication, i.e. changing patterns of drinking in the individuals and populations at large, is an important objective of primary prevention of alcohol use disorders. ${ }^{2}$ Many countries use licenses issued by the government to control the sale of alcohol. These licenses can be cancelled if the law is broken. ${ }^{25}$ A number of studies have reported a significant impact of outlet density on alcohol consumption and drunkdriving collisions. According to the WHO, South Africa currently employs restrictions on the number of retail outlets, but there are no proper restrictions on the density of outlets. ${ }^{25}$

There is need to regulate the days and hours when liquor sales should be permitted. In zoned areas, South Africa currently imposes restrictions on hours of retail sales. ${ }^{32}$ The Western Cape Liquor Act, for example, states the maximum opening and closing times for on-and off-premises consumption as $11 \mathrm{am}$ to $2 \mathrm{am}$ and $9 \mathrm{am}$ to $6 \mathrm{pm}$ respectively, and Cape Town is considering restricting these hours further, and plans to restrict trade on Sundays and public holidays. ${ }^{25}$ In India, an alcohol ban exists in some states, making the manufacture, sale, transportation, consumption and storage of alcohol illegal. States that have implemented and enforced the ban on alcohol in the country include Gujarat, Nagaland, Lakshadweep, Kerala, Manipur and Bihar. ${ }^{33,34}$

\section{Restrictions on the minimum legal drinking age}

Increasing the legal drinking age can reduce alcohol sales and problems among young drinkers. ${ }^{25}$ In India the minimum legal drinking age varies from state to state (from 18-25 years): it is 25 years in Delhi and 21 in Uttar Pradesh. The minimum drinking age is 18 in South Africa, which is in line with international practice. ${ }^{32}$ To realize its full benefits, it is essential to enforce the age limit laws by the governments with the support of civil society, NGOs, producers and retailers of alcoholic 
beverages. The most direct approach to the enforcement of the age limit laws is through a requirement for identification such as national identity cards, passports or driver's licenses at points of sale. ${ }^{32,35}$ To effectively enforce this policy, focus should be on sellers, who could be made to face closure for noncompliance. ${ }^{25}$ To prevent young people from consuming alcohol, it is essential to make efforts in the form of awareness and counselling aimed directly at young people and also at those adults who facilitate their access to alcohol. ${ }^{35}$

\section{Roadblocks and Random (unrestricted) breath testing}

In South Africa, the new Road Safety Strategy includes plans to increase enforcement, particularly in the form of mini roadblocks as well as multidisciplinary roadblocks. Roadblocks can identify drivers driving under the influence of drugs or alcohol. ${ }^{22}$ Administrative license suspension and a reduction of the blood alcohol content (BAC) levels lowers the incidence of drinkdriving behavior at all levels, and has also led to further reductions in alcohol-related road traffic accidents. ${ }^{2}$ Most countries have a BAC limit of either 0.05 or $0.08 \mathrm{~g} /$ $100 \mathrm{ml}$ for drivers. The BAC limit for drivers has been specified in both countries. However, South Africa has different limits based on the type of drivers, while India has a uniform limit (Table 2). ${ }^{25}$

\section{Health warning labels}

In India, some states mandate a health warning on liquor bottles while others do not. ${ }^{1}$ In South Africa, containers for alcoholic beverages must now contain one of the seven health messages shown in Table 4, and these must be at least one-eighth of the total size of the container label. ${ }^{36}$ There is no requirement that messages are rotated. The liquor industry has even introduced its own health warnings on alcohol (e.g. 'No sales to persons under 18') in order to influence the government to counter calls for greater governmental regulation. ${ }^{37}$

Table 4: Health messages for alcoholic beverages, South Africa

\section{Alcohol reduces driving ability \\ Don't drink and drive \\ Don't drink and walk on the road \\ You may be killed}

Alcohol increases your risk to personal injuries

Alcohol is a major cause of violence and crime

Alcohol abuse is dangerous to your health; alcohol is addictive Drinking during pregnancy can be harmful to your unborn baby

Source: Global Agricultural Information network. Regulation amendment on container labels of alcoholic beverages. ${ }^{46}$

Indian Journal of Pharmacy Practice, Vol 9, Issue 2, Apr-Jun, 2016

\section{Educational interventions}

Community-wide interventions in the form of creating awareness at community level; engaging community members in action around alcohol problems; providing information on alcohol; positively engaging youths in and out of school; promoting responsible use, treatment and rehabilitation can be used. ${ }^{18}$ Educational and awareness campaigns on the harmful use of alcohol would help to control the harmful use of alcohol, as educated individuals would act in their own long-term interests, even when faced with heavy marketing and promotion. ${ }^{4}$

Ensuring healthy lives and to promoting the well-being for all at all ages is essential to sustainable development. Health promotion has the potential to empower people to develop or maintain healthy lifestyles; reduces excess mortality; addresses the leading risk factors and underlying determinants of health; helps to strengthen sustainable health systems; and is important in achieving the targets for SDG 3, by increasing awareness of the consequences of harmful use of alcohol. ${ }^{38,39}$ Carrying out health promotion in settings where people live, work, learn and play is a creative and effective way of improving their health and quality of life. Health promotion has a crucial role to play in fostering healthy public policies and health-supportive environments, enhancing positive social conditions and personal skills, and promoting healthy lifestyles. ${ }^{38}$ There is evidence that comprehensive interventions targeted towards special populations such as pregnant drinkers could also have a positive impact. ${ }^{2}$ Community-Based Participatory Research (CBPR) is a collaborative approach that offers opportunities to engage people as active contributors, equitably involves all partners in the research process, and those that are affected and know of the local circumstances that affect health. ${ }^{40,41}$ CBPR is an effective way to understand health issues, in their respective social and environmental contexts in which these issues are embedded. ${ }^{42}$

\section{CONCLUSION}

The harmful use of alcohol can be decreased through the introduction of national policies and also by using a bottom-up approach, by implementing interventions in the community. As alcohol use affects sustainable development, different policies and interventions have been introduced and implemented in both South Africa and India, but alcohol use continues to rise in both countries. India does not have a national policy on alcohol, as alcohol is a state subject and, in some states, the policies that exist prioritise the revenue generated by alcohol sales. Alcohol use in India is a major public health problem affecting individuals, families, society and the nation, and a national policy is thus important. South 
Africa has a national policy that uses the WHO framework, but for alcohol harm to decrease, these policies need to be enforced more effectively.

\section{ACKNOWLEDGEMENT}

The authors gratefully acknowledge Rhodes University for all of its support.

\section{CONFLICT OF INTEREST}

The author declare no conflict of interest.

\section{ABBREVIATIONS USED}

AIDS: Acquired immunodeficiency syndrome; BAC: Blood Alcohol Content; CBPR: Community-Based Participatory Research; DALY: Disability-adjusted life year; FASD: Fetal alcohol spectrum disorders; GBD: Global Burden of Disease; HIC: High-Income Countries; HIV: Human immunodeficiency Virus; LMICs: lowand middle-income countries; MEC: Member of the Executive Council; MDGs: Millennium Development Goals; NDMP: National Drug Master Plan; NGO: Non-governmental organization; NLA: National Liquor Authority; NLPC: National Liquor Policy Council; NCD: Non-communicable diseases; SDGs: Sustainable Development Goals; WHA: World Health Assembly; WHO: World Health Organization.

\section{REFERENCES}

1. Endal D. Alcohol Marketing and Regulatory Policy Environment in India - ADD Resources [Internet]. 2014 [cited 2016 Feb 12]. Available from: http://www. add-resources.org/alcohol-marketing-and-regulatory-policy-environment-inindia.5435861-315784.html

2. Poznyak VB. The role of psychiatrists in prevention of psychoactive substance use and dependence: beyond clinical practice. World Psychiatry. 2005;4(1):31-2.

3. Indian Alcohol Policy Alliance. Alcohol related harm in india - a fact sheet [Internet]. [cited 2016 Feb 12]. Available from: http://www.addictionindia.org/ images-ttkh/alcohol-related-harm-in-india-a-fact-sheet.pdf

4. Room R, Rehm J, Parry C. Alcohol and non-communicable diseases (NCDs): time for a serious international public health effort. Addiction. 2011;106(9):1547-8.

5. WHO Europe. What are the most effective and cost-effective interventions in alcohol control? - E82969.pdf [Internet]. 2004 [cited 2016 Mar 16]. Available from: http://www.euro.who.int/_data/assets/pdf_file/0020/74702/E82969.pdf

6. WHO. Millennium Development Goals (MDGs) [Internet]. WHO. 2016 [cited 2016 Mar 15]. Available from: http://www.who.int/topics/millennium development_goals/about/en/

7. WHO. From MDGs to SDGs [Internet]. 2015 [cited 2016 Mar 15]. Available from: http://www.who.int/mediacentre/events/meetings/2015/MDGs-SDGs-Summary.pdf

8. IOGT International. The Overlooked Obstacles for Achieving Millenium Development Goals [Internet]. 2012 [cited 2016 Apr 8]. Available from: http://us2.campaign-archive1.com/?u=208eb41381d07b9517fc37d74 \&id=9051a69d66\&e=0bf5d0d1fa

9. Singh JG, Raja AP, Shalini F. Millennium development goals: A social science perspective , Allied Publishers, New Delhi. Sahn, D.E. \& Stifel, D.C., 2003. Progress toward the Millennium development goals in Africa. World Development. 2009;31(1): 23-52.

10. WHO. Sustainable Development Goal 3: Health [Internet]. WHO. 2016 [cited 2016 Mar 18]. Available from: http://www.who.int/topics/sustainabledevelopment-goals/targets/en/
11. Stuckler D, McKee M, Ebrahim S, Basu S. Manufacturing Epidemics: The Role of Global Producers in Increased Consumption of Unhealthy Commodities Including Processed Foods, Alcohol, and Tobacco. PLoS Med. 2012;9(6):e1001235.

12. Van Walbeek $C$, Blecher $E$. The economics of alcohol use, misuse and policy in south africa [Internet]. 2014 [cited 2016 Feb 12]. Available from: http:// tobaccoecon.org/wp-content/uploads/2014/03/the-economics-of-alcoholpolicy-in-south-africa.pdf

13. Peltzer K, Davids A, Njuho H. Alcohol use and problem drinking in South Africa: a finding from a national population-based survey [Internet]. [cited 2016 Feb 15]. Available from: https://africacheck.org/wp-content/uploads/2013/03/ peltzer-article-SA-Alcohol-use-and-problem-drinking.pdf

14. WHO. Alcohol country profiles - South Africa [Internet]. 2014 [cited 2016 Mar 17]. Available from: http://www.who.int/substance_abuse/publications/global_ alcohol_report/profiles/zaf.pdf

15. Seggie J. Alcohol and South Africa's Youth. S Afr Med J. 2012;102(7):587.

16. Gupta H. Alcohol use and gaps in it's existing regulatory in India: A review [Internet]. [cited 2016 Feb 16]. Available from: https://www. eiseverywhere.com/file_uploads/149e1cb1e51afe47d45ddd917c81aeb3_ HimanshuGuptaAPSADposter.pdf

17. WHO. Country Profiles- India [Internet]. 2014 [cited 2016 Mar 17]. Available from: http://www.who.int/substance_abuse/publications/global_alcohol_report/ profiles/ind.pdf

18. Setlalentoa M, Ryke E, Strydom $H$. Intervention strategies used to address alcohol abuse in the North West province, South Africa. Soc Work. 2015;51(1):80-100.

19. WHO. Harmful use [Internet]. WHO. 2016 [cited 2016 Mar 17]. Available from: http://www.who.int/substance_abuse/terminology/definition2/en/

20. Institute of Alcohol studies. Indian Government urged to formulate National Alcohol Policy [Internet]. 2010 [cited 2016 Apr 18]. Available from: http://www. ias.org.uk/What-we-do/Publication-archive/The-Globe/Issue-1-2010/IndianGovernment-urged-to-formulate-National-Alcohol-Policy.aspx

21. Greenfacts. Scientific Facts on Alcohol [Internet]. 2015 [cited 2016 Feb 15]. Available from: http://www.greenfacts.org/en/alcohol/alcohol-greenfacts-level2.pdf

22. Department of social development. Specific interventions by government departments [Internet]. [cited 2016 Feb 12]. Available from: http://www.dsd.gov. za/cda/index.php?option=com_content\&task=view\&id=110\&ltemid=138

23. Parry C. Substance abuse intervention in South Africa. World Psychiatry. 2005;4(1):34-5.

24. MRC. Fetal Alcohol Spectrum disorders in Capetown, South Africa [Internet]. [cited 2016 Feb 12]. Available from: http://www.mrc.ac.za/policybriefs/ FetalAlcoholSpectrum.pdf

25. Marais C, Fourie $\mathrm{H}$. The External Cost of Alcohol Consumption in South Africa: Ban on Alcohol Advertising versus other Appropriate Intervention Policies [Internet]. 2014 [cited 2016 Feb 12]. Available from: http://econex.co.za/wpcontent/uploads/2015/03/econex_researchnote_33.pdf

26. Department of social development. National drug masterplan [Internet]. 2013 [cited 2016 Feb 15]. Available from: http://www.dsd.gov.za/index2. php?option=com_docman\&task $=$ doc_view\&gid $=414 \& \mid$ temid $=3$

27. WHO. Global status report on alcohol and health [Internet]. 2011 [cited 2016 Feb 16]. Available from: http://www.who.int/substance_abuse/publications/ global_alcohol_report/msbgsruprofiles.pdf

28. International Center for Alcohol Policies. Guide to Creating Integrative Policies. pdf [Internet]. 2008 [cited 2016 Apr 15]. Available from: http://www.icap.org/ Portals/0/download/all_pdfs/Policy\%20Tools/Guide\%20to\%20Creating\%20 Integrative\%20Policies.pdf

29. International Center for Alcohol Policies. Toolkit for working together [Internet]. [cited 2016 Apr 15]. Available from: http://webcache.googleusercontent com/search?q=cache:ELNIMugioTYJ:www.icap.org/LinkClick. aspx\%3Ffileticket\%3D1ZAhRFc6Gcg\%253D\%26tabid\%3D541+ $\& \mathrm{~cd}=4 \& \mathrm{hl}=\mathrm{en} \& \mathrm{ct}=\mathrm{clnk} \& \mathrm{gl}=\mathrm{za}$

30. Public Health Foundation of India. Alcohol Marketing and Regulatory Policy Environment in India [Internet]. 2013 [cited 2016 Mar 17]. Available from: http:// iogt.org/wp-content/uploads/2013/12/PHFI-Alcohol-Industry-Report.pdf

31. Home office. The likely impacts of increasing alcohol price: a summary review of the evidence base [Internet]. 2011 [cited 2016 Apr 18]. Available from: http://webarchive.nationalarchives.gov.uk/+/http:/www.homeoffice.gov.uk/ publications/alcohol/impacts-alcohol-price-review?view=Binary

32. National liquor policy [Internet]. 2015 [cited 2016 Feb 12]. Available from: http:// www.gov.za/sites/www.gov.za/files/38808_gen446.pdf 
33. Bihar goes "dry", sale of liquor banned - Times of India [Internet]. The Times of India. 2016 [cited 2016 Apr 14]. Available from: http://timesofindia.indiatimes. com/city/patna/Bihar-goes-dry-sale-of-liquor-banned/articleshow/51701042.cms

34. The Indian Express. States with total and phase-wise prohibition of alcohol in India [Internet]. 2016 [cited 2016 Apr 8]. Available from: https://in.news.yahoo. com/states-total-phase-wise-prohibition-111500774.html

35. Global actions. Regulatory framework to prevent underage drinking: A REVIEW [Internet]. 2013 [cited 2016 Apr 18]. Available from: http:// www.producerscommitments.org/wp-content/uploads/2015/09/ UnderageDrinkingReview.pdf

36. Thomas G, Gonneau G, Poole N, Cook J. The effectiveness of alcohol warning labels in the prevention of Fetal Alcohol Spectrum Disorder: A brief review. Int $\mathrm{J}$ Alcohol Drug Res. 2014;3(1):91.

37. Edayaranmula J. Alcohol Policy And Challenges In India [Internet]. IOGT International. 2013 [cited 2016 Feb 12]. Available from: http://iogt.org/ blog/2013/09/29/test/

38. WHO. WHO | Health promotion [Internet]. WHO. 2016 [cited 2016 Mar 18]. Available from: http://www.who.int/topics/health_promotion/en/

39. Lood Q, Häggblom-Kronlöf G, Dahlin-Ivanoff S. Health promotion programme design and efficacy in relation to ageing persons with culturally and linguistically diverse backgrounds: a systematic literature review and meta-analysis. BMC Health Serv Res. 2015;15(1):1-10.

40. Hartwig K, Calleson D, Williams M. Community-Based Participatory Research: Getting Grounded. In: The Examining Community-Institutional Partnerships for Prevention Research Group. Developing and Sustaining Community-Based
Participatory Research Partnerships: A Skill-Building Curriculum [Internet]. 2006 [cited 2016 Mar 17]. Available from: https://depts.washington.edu/ccph/ cbpr/u1/u11.php

41. Israel B, Schulz A, Parker E, Becker A. Review of community-based research: Assessing Partnership Approaches to Improve Public Health. Annu Rev Public Health. 1998;19(1):173-202.

42. Mosavel M, Simon C, van Stade D, Buchbinder M. Community-based participatory research (CBPR) in South Africa: Engaging multiple constituents to shape the research question. Soc Sci Med. 2005;61(12):2577-87.

43. WHO. Noncommunicable Diseases (NCD) Country Profiles - South Africa [Internet]. 2014 [cited 2016 Mar 18]. Available from: http://www.who.int/nmh/ countries/zaf_en.pdf

44. WHO. Global status report on non-communicable diseases 2014 [Internet]. 2014 [cited 2016 Apr 15]. Available from: http://apps.who.int/iris/ bitstream/10665/148114/1/9789241564854_eng.pdf

45. WHO. Global alcohol report- Country profiles [Internet]. WHO. 2014 [cited 2016 Feb 15]. Available from: http://www.who.int/substance_abuse/publications/ global_alcohol_report/msb_gsr_2014_2.pdf?ua=1

46. Global Agricultural Information network. Regulation amendment on container labels of alcoholic beverages_Pretoria_South Africa - Republic of_1-30-2015. pdf [Internet]. 2015 [cited 2016 Apr 5]. Available from: http://gain.fas.usda. gov/Recent\%20GAIN\%20Publications/Regulation\%20amendment\%20on\%20 container\%20labels\%20of\%20alcoholic\%20beverages_Pretoria_South\%20 Africa\%20-\%20Republic\%20of_1-30-2015.pdf 